\title{
Right coronary artery arising as a terminal extension of the left circumflex artery (a rare coronary artery anomaly)
}

\author{
Halil Tanrıverdi MD, Deniz Şeleci MD, Ömür Kuru MD, Ender Semiz MD
}

\begin{abstract}
H Tanrıverdi, D Şeleci, Ö Kuru, E Semiz. Right coronary artery arising as a terminal extension of the left circumflex artery (a rare coronary artery anomaly). Can J Cardiol 2007;23(9):737-738.

A single coronary artery is a very rare type of coronary artery anomaly that may present in various forms. A patient is presented in whom the right coronary artery coursed as the terminal branch of the left circumflex artery. This is the second case of this anomaly in the literature.
\end{abstract}

Key Words: Coronary angiography; Coronary artery anomaly; Single coronary artery

Tongenital coronary artery anomalies are infrequently seen during coronary angiographic study, reported to occur in $0.64 \%$ to $1.3 \%$ of patients (1). Most patients with a congenital coronary artery anomaly are asymptomatic; in rare cases, they may present with chest pain and have myocardial ischemia or other life-threatening conditions. We present a patient in whom the right coronary artery (RCA) coursed as the terminal branch of the left circumflex (LCx) artery. This anomaly is a very rare type of single coronary artery anomaly form.

\section{CASE PRESENTATION}

A 79-year-old woman was admitted to the Department of Cardiology at the Pamukkale University School of Medicine (Denizli, Turkey) with atypical chest pain. She had no family history or other risk factors associated with coronary artery disease. Cardiac auscultation and peripheral pulses at the radial, popliteal, posterior tibial and dorsalis pedis arteries were normal. A resting electrocardiogram (ECG) demonstrated precordial $\mathrm{T}$ wave inversion. An echocardiogram revealed normal left ventricular morphology and no abnormal regional wall motion. The investigators decided to perform coronary angiography to determine the reason for the ECG abnormality. Aortography obtained in the left anterior-oblique projection revealed absence of the ostium of the right coronary artery in the right sinus of Valsalva (Figure 1). The left coronary ostium was observed to be normal in the left sinus of Valsalva. Selective left coronary angiography revealed normal origin and course of the left main (LM), the LCx and the left anterior descending (LAD) arteries. The LCx artery did not terminate after reaching the crux; giving rise to the posterior descending branch, it coursed in the right atrioventricular groove as if it were the RCA (Figure 2). This vessel terminated when it reached the right sinus of Valsalva (Figure 3). There was a stenosis of $50 \%$ in the midportion of the LAD artery, although

\section{L'artère coronaire droite en prolongement terminal de l'artère circonflexe (une anomalie rare de l'artère coronaire)}

Une artère coronaire unique est un type très rare d'anomalie de l'artère coronaire, qui peut prendre diverses formes. Le cas d'un patient est présenté, chez qui l'artère coronaire droite était une terminaison de l'artère circonflexe. C'est le deuxième cas d'une telle anomalie dans les publications scientifiques.

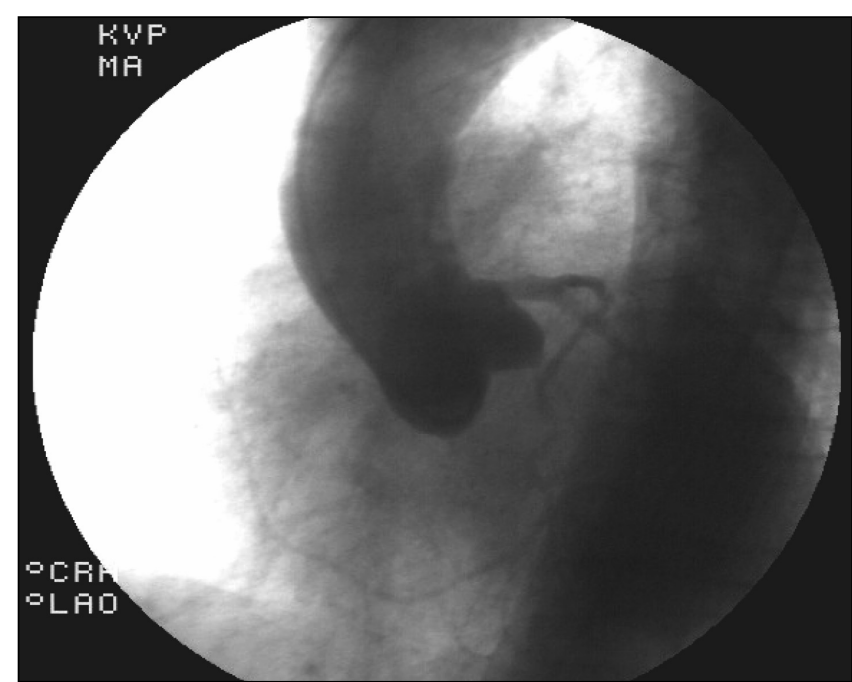

Figure 1) Aortography in the left anterior oblique view. Right coronary ostium is not seen in the right sinus of Valsalva

a pressure wire study showed no critical functional stenosis. The left ventriculography was normal.

\section{DISCUSSION}

Coronary artery anomalies are a group of disorders with various severities, ranging from mild variations to marked anatomical abnormalities and from asymptomatic status to a life-threatening condition. They are present at birth, and relatively few patients are symptomatic during childhood. Most anomalies are discovered as incidental findings during coronary angiographic study or autopsy, with a $0.64 \%$ to $1.3 \%$ incidence rate reported in the literature $(1,2)$. Yamanaka and Hobbs (1) described 126,595 patients undergoing cardiac 


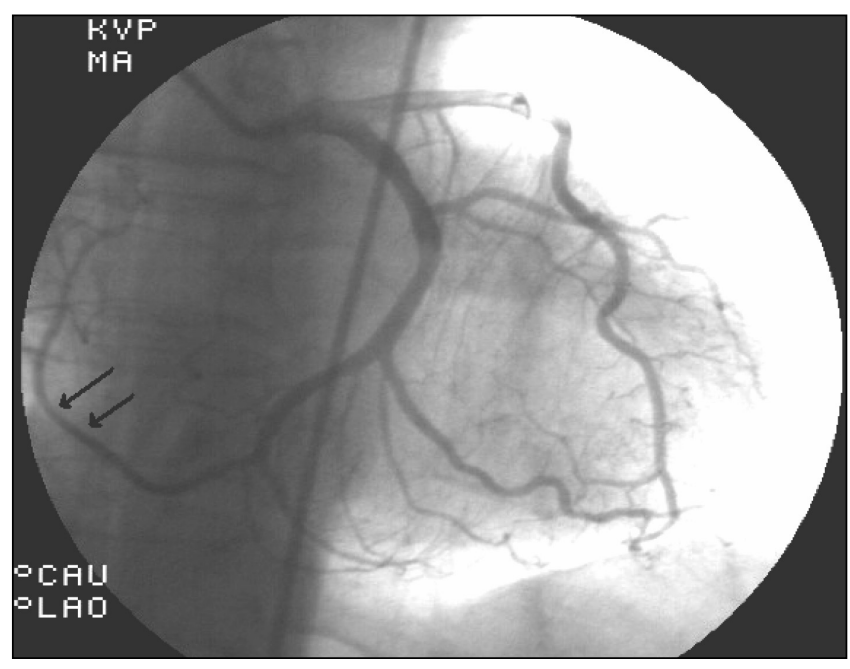

Figure 2) The single coronary artery visualized in the left caudal angulation. The right coronary artery arises as the terminal extension of the circumflex artery and travels to the right ventricle area (arrows indicate the right coronary artery)

catheterization between 1960 and 1988, the largest study in the literature (1). Separate origins of the LAD and the LCx arteries from the left sinus of Valsalva is the most common anomaly, occurring in approximately $0.41 \%$ of patients studied. The RCA arising as a branch from the midportion of the LAD artery is a very rare anomaly. Only six adult cases have been reported in the literature (3-8). However, only one case with the RCA arising as a terminal extension of the LCx artery has been reported in the literature (9).

There are various classifications of single coronary artery anomalies. According to the widely used classification described by Lipton et al (10), the coronary artery system was classified as $\mathrm{L}$ when the single coronary artery originated from the left sinus of Valsalva and $\mathrm{R}$ when it originated from the right sinus of Valsalva. If the RCA arises as a terminal extension of the $\mathrm{LCx}$ artery, it is classified under the LI subgroup. LIIA, LIIB and LIIP subgroups represent the RCA branching from the LM, LCx and LAD arteries, respectively. Our case was classified under the subgroup LI. Increased sudden death risk is reported in patients with a single coronary artery in whom the LM artery lies

\section{REFERENCES}

1. Yamanaka O, Hobbs RE. Coronary artery anomalies in 126,595 patients undergoing coronary arteriography. Cathet Cardiovasc Diagn 1990;21:28-40.

2. Ueyama K, Ramchandani M, Beall AC, Jones JW. Diagnosis and operation for anomalous circumflex coronary artery. Ann Thorac Surg 1997;63:377-81.

3. Biffani G, Lioy E, Loschiavo P, Parma A. Single coronary artery, anomalous origin of the right coronary artery from the left anterior descending artery. Eur Heart J 1991;12:1326-9.

4. Simkoff WL, Murphy ES, DeMots H, Khonsari S, Abbruzzese P. Anomalous origin of the right coronary artery from the left anterior descending: Angiographic diagnosis in a patient with coronary artery disease. Cathet Cardiovasc Diagn 1982;8:49-53.

5. Habbab MA, Senft AG, Haft JL. Origin of the right coronary artery from the left anterior descending coronary artery: A very rare anomaly of coronary arterial origin. Am Heart J 1987;114:169-70.

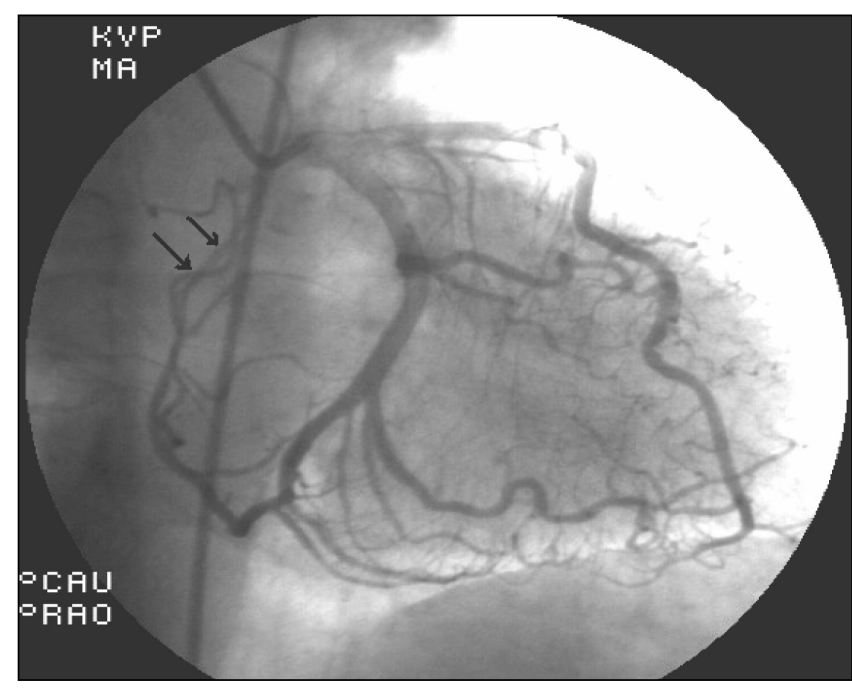

Figure 3) Right caudal view of the right coronary artery. This vessel terminated when it reached the right sinus of Valsalva (arrows indicate the right coronary artery)

between the aorta and the pulmonary artery. The clinical course of the case in which a coronary artery arises as the terminal extension of another, such as in our case, is relatively benign.

There is no clear evidence indicating the relationship between atherosclerosis and coronary arteries with abnormal origin and course. On the other hand, depending on the character of the coronary anomaly, patients may survive asymptomatically until coronary atherosclerosis progresses and leads to clinically evident coronary artery disease. During the initial clinical evaluation of our case, we suspected coronary artery disease because of the $\mathrm{T}$ wave abnormalities and, thus, we performed coronary angiography. Coronary angiography revealed a 50\% lesion in the midportion of the LAD artery. In addition to the coronary artery anomaly, we believed that there was no relationship between the ECG findings and the coronary artery anomaly. A pressure wire study was performed, but showed no critical functional stenosis. No therapy was prescribed.

In conclusion, the present report described a subject with an RCA originating from the LCx artery.

6. Molajo AO, Bray CL. Accelerated atherosclerosis and myocardial infarction complicating anomalous origin of the right from the left coronary artery. Int J Cardiol 1989;23:409-12.

7. Nath A, Kennett JD, Politte LL, Sanfelippo JF, Alpert MA. Anomalous right coronary artery arising from the midportion of the left anterior descending coronary artery - case reports. Angiology 1987;38:142-6.

8. Iyisoy A, Kursaklioglu H, Barcin C, Barindik N, Kose S, Demirtas E. Single coronary artery with anomalous origin of the right coronary artery as a branch from the left anterior descending artery: A very rare coronary anomaly. Heart Vessels 2002;16:161-3.

9. Turhan H, Duru E, Yetkin E, Atak R, Senen K. Right coronary artery originating from distal left circumflex: An extremely rare variety of single coronary artery. Int J Cardiol 2003;88:309-11.

10. Lipton MJ, Barry WH, Obrez I, Silverman JF, Wexler L. Isolated single coronary artery: Diagnosis, angiographic classification, and clinical significance. Radiology 1979;130:39-47. 